\title{
Enhanced IFN-a production is associated with increased TLR7 retention in the lysosomes of palasmacytoid dendritic cells in systemic lupus erythematosus
}

\author{
Goh Murayama ${ }^{1,2+}$, Nanako Furusawa $^{1+}$, Asako Chiba $^{1 *}$, Ken Yamaji ${ }^{2}$, Naoto Tamura $^{2}$ and Sachiko Miyake ${ }^{1 *}$
}

\begin{abstract}
Background: Interferon-a (IFN-a) is increased and plays an important role in the pathogenesis of systemic lupus erythematosus (SLE). Plasmacytoid dendritic cells (pDCs) are the main producer of IFN- $a$, but their IFN-a producing capacity has been shown to be unchanged or reduced when stimulated with a Toll-like receptor 9 (TLR9) agonist in patients with SLE compared to in healthy individuals. In this study, we investigated the IFN-a-producing capacity of lupus pDCs under different stimulation.

Methods: pDCs from patients with SLE and healthy controls $(\mathrm{HC})$ were stimulated with TLR9 or TLR7 agonist, and their IFN-a producing capacity was examined by intracellular cytokine staining and flow cytometry. The correlation of IFN-a-producing capacity with serum IFN-a levels and disease activity was assessed. The effect of in vitro IFN-a exposure on IFN-a production by pDCs was examined. Localization of TLR7 in cellular compartments in pDCs was investigated.
\end{abstract}

Results: The IFN-a producing capacity of pDCs was reduced after TLR9 stimulation, but increased when stimulated with a TLR7 agonist in SLE compared to in HC. IFN-a production by pDCs upon TLR9 stimulation was reduced and the percentage of IFN- $\mathrm{a}^{+} \mathrm{pDC}$ was inversely correlated with disease activity and serum IFN-a levels. However, the TLR7 agonist-induced IFN-a producing capacity of lupus pDCs was enhanced and correlated with disease activity and serum IFN-a. Exposure to IFN-a enhanced IFN-a production of TLR7-stimulated pDCs, but reduced that of pDCs activated with a TLR9 agonist. TLR7 localization was increased in late endosome/lysosome compartments in pDCs from SLE patients.

Conclusions: These findings indicate that enhanced TLR7 responses of lupus pDCs, owing to TLR7 retention in late endosome/lysosome and exposure to IFN-a, are associated with the pathogenesis of SLE.

Keywords: Systemic lupus erythematosus, Toll-like receptor, Interferon-a, Plasmacytoid dendritic cells

\section{Background}

Type I interferons (IFNs) including IFN- $\alpha$ are known to play important roles in the pathogenesis of systemic lupus erythematosus (SLE) [1-3]. Over expression of type I IFNs has been shown to accelerate production of autoantibodies and tissue damage in lupus-prone mice [4]. Deletion of the

\footnotetext{
* Correspondence: a-chiba@juntendo.ac.jp; s-miyake@juntendo.ac.jp ${ }^{\dagger}$ Equal contributors

${ }^{1}$ Department of Immunology, Juntendo University School of Medicine, 2-2-1 Hongo, Bunkyo-ku, Tokyo 113-8421, Japan

Full list of author information is available at the end of the article
}

type I IFN receptor results in reduced autoantibody production and disease severity [5,6]. Treatment of patients with hepatitis $C$ virus or cancer with type I IFN induces lupus-like disease [7-9]. Early studies showed that the levels of type I IFN or IFN-inducible genes in peripheral blood mononuclear cells (PBMCs) are increased in patients with SLE, and that the levels of IFN- $\alpha$ are associated with disease severity [10-19]. Genome-wide association studies have shown that molecules involved in the production of type I IFN affect SLE susceptibility [20-22]. Lupusassociated single-nucleotide polymorphisms are found in 
genes encoding molecules that participate in the production of IFN- $\alpha$, such as Toll-like receptor (TLR) 7, IFN-regulatory factor (IRF) 5, and IRF7 [23-30]. Lupusassociated single-nucleotide polymorphisms in IRF7, IRF5, and STAT4 are related to elevated levels of IFN- $\alpha$, and some SLE risk haplotypes of IRF5 have been shown to be associated with increased IFN- $\alpha$ expression in SLE [27, 31].

Plasmacytoid dendritic cells (pDCs) are the main producers of IFN- $\alpha$ [32-35]. IFN- $\alpha$ production by human pDCs occurs mostly through the TLR7 and TLR9 signaling pathways. Under physiological conditions, TLR7 recognizes single-strand RNA and TLR9 responds to DNA from viruses or bacteria. In SLE, immune complexes composed of autoantibodies and DNA or RNA have been shown to induce IFN- $\alpha$ production by pDCs [36-39]. Although many studies have demonstrated an increase in serum IFN- $\alpha$ levels or IFN-inducible genes in SLE, as to whether the IFN- $\alpha$-producing capacity of pDCs is enhanced in SLE remains unclear. IFN- $\alpha$ production by $\mathrm{CD}_{123^{+}}$cells after stimulation with influenza virus is comparable between SLE patients and healthy donors [40]. Other reports show that IFN- $\alpha$ production by PBMCs or pDCs after stimulation with herpes simplex virus, Sendai virus, or $\mathrm{CpG}$ oligodeoxyribonucleotide $(\mathrm{ODN})$ is reduced in patients with SLE [41-45]. These findings suggest that the IFN- $\alpha$-producing capacity of lupus pDCs varies depending on the type of stimuli.

In the current study, we investigated the IFN- $\alpha$ producing capacity by pDCs after stimulation with TLR7 or TLR9 agonists. IFN- $\alpha$ production by $\mathrm{pDCs}$ upon TLR9 stimulation was reduced, and the percentage of IFN- $\alpha^{+} \mathrm{pDCs}$ was inversely correlated with disease activity and serum IFN- $\alpha$ levels. However, the IFN- $\alpha-$ producing capacity of lupus pDCs was enhanced following stimulation with a TLR7 agonist and correlated with disease activity and serum IFN- $\alpha$. This is the first study demonstrating enhanced IFN- $\alpha$ producing capacity of lupus pDCs. We also found that prior exposure to IFN$\alpha$ enhanced the IFN- $\alpha$ producing capacity of pDCs after stimulation with a TLR7 agonist, but reduced TLR9 agonist-induced IFN- $\alpha$ production by pDCs. Finally, we demonstrate that enhanced IFN- $\alpha$ production by TLR7stimulated pDCs was associated with increased retention of TLR7 in late endosome/lysosome compartments in lupus pDCs. Thus, the enhanced IFN- $\alpha$-producing capacity of pDCs, owing to increased TLR7 in late endosome/lysosome compartments, is augmented by exposure to IFN- $\alpha$ during active disease.

\section{Methods}

\section{Subjects}

Our study with flow cytometric analysis included 71 patients diagnosed with SLE (66 women and 5 men, median age (interquartile range (IQR)) 36.0 years (22.0$60.0)$ ) and 45 healthy controls (HC) (41 women and 4 men, median age 36.0 years (21.0-56.0)). The study with confocal microscopic analysis included six patients with SLE and five HCs (Additional file 1: Table S1). We obtained peripheral blood from patients with SLE and $\mathrm{HC}$ after obtaining informed consent in accordance with the local ethical committee guidelines of Juntendo University. SLE was diagnosed according to the American College of Rheumatology criteria for SLE. HC did not have a history of any autoimmune disease and had never received immunosuppressive therapy. Informed consent was obtained from all patients with SLE and all $\mathrm{HC}$ according to the ethical guidelines for human subject research. Disease activity was assessed by the SLE Disease Activity Index 2000 (SLEDAI-2 K) [46]. Active disease was defined as a SLEDAI-2 K score $>4$. The ages, sex, and treatments of the patients are presented in Table 1.

Table 1 Characteristics of healthy controls $(\mathrm{HC})$ and patients with systemic lupus erythematosus (SLE)

\begin{tabular}{|c|c|c|}
\hline & $\mathrm{HC}$ & SLE \\
\hline Number & 45 & 71 \\
\hline Female/male, $n$ & $41 / 4$ & $66 / 5$ \\
\hline Age, years & $36.0(21.0-56.0)$ & $36.0(22.0-60.0)$ \\
\hline Disease duration, years & & $7.0(0.0-31.0)$ \\
\hline Anti-DNA antibody (IU/mL) & & $3.5(2.0-300.0)$ \\
\hline C3 (mg/dL) & & $67.0(9.0-195.0)$ \\
\hline $\mathrm{CH} 50(\mathrm{U} / \mathrm{mL})$ & & $29.4(2.0-78.1)$ \\
\hline SLEDAI score & & $4.0(2.0-34.4)$ \\
\hline SLEDAI $<5, n$ & & 41 \\
\hline SLEDAI $\geq 5, n$ & & 30 \\
\hline \multicolumn{3}{|l|}{ Disease } \\
\hline Glomerulonephritis, n & & 37 \\
\hline Arthritis, $n$ & & 11 \\
\hline Neuropsychiatric SLE, $n$ & & 8 \\
\hline Pancytopenia, $n$ & & 6 \\
\hline Lupus enteritis, $n$ & & 5 \\
\hline Cutaneous lupus erythematosus, $n$ & & 3 \\
\hline Pneumonitis, $n$ & & 1 \\
\hline \multicolumn{3}{|l|}{ Medications } \\
\hline Medication naïve, $n$ & & 10 \\
\hline Prednisone, $n$ & & 57 \\
\hline Prednisone dose (mg/day) & & $7.0(2.0-45.0)$ \\
\hline Immunosuppressive agent ${ }^{\mathrm{a}}, n$ & & 19 \\
\hline
\end{tabular}

Values are number or median (interquartile range) SLEDAI Systemic Lupus Erythematosus Disease Activity Index 2000

${ }^{a}$ Azathioprine, mizoribine, mycophenolate mofetil, tacrolimus 


\section{Flow cytometry}

Fresh PBMCs were isolated from whole blood by densitygradient centrifugation using the BD Vacutainer CPT Mononuclear Cell Preparation Tubes with Sodium Heparin (BD Biosciences, Franklin Lakes, NJ, USA). The cells were first stained using the Zombie Yellow ${ }^{\mathrm{Tm}}$ Fixable Viability Kit (BioLegend, San Diego, CA, USA) and then with combinations of the following monoclonal antibodies against human cell-surface antigens for $30 \mathrm{~min}$ on ice: anti-CD11c-Alexa700, anti-HLADR-V500, anti-CD19APC-H7 (all from BD Biosciences), anti-CD14-ECD, antiCD56-APC, (both from Beckman Coulter, Brea, CA, USA), anti-CD123-FITC, anti-CD3- PerCPCy5.5, antiCD56-BV421 (all from BioLegend), and anti-CD19-PE (TONBO Biosciences, San Diego, CA, USA). pDCs were identified as $\mathrm{CD}^{-} \mathrm{CD} 19^{-} \mathrm{CD} 14^{-} \mathrm{CD} 56^{-} \mathrm{HLADR}^{+} \mathrm{CD} 11 \mathrm{c}^{-}$ $\mathrm{CD}_{123}{ }^{+}$(Additional file 2: Figure S1). Data were acquired on a FACS LSR Fortessa (BD Biosciences) and the percentages of each cell population and mean fluorescence intensity were analyzed using FlowJo software (TreeStar Inc., Ashland, OR, USA).

\section{TLR stimulation and intracellular cytokine staining}

PBMCs were cultured in 96-well flat-bottom plates in Basal Medium Eagle (Thermo Fisher Scientific, Waltham, MA, USA) supplemented with $10 \%$ fetal bovine serum, $2 \mathrm{mM}$ L-glutamine, $50 \mathrm{U} / \mathrm{mL}$ penicillin, and $50 \mu \mathrm{g} / \mathrm{mL}$ streptomycin (all from Thermo Fisher Scientific). PBMCs were stimulated with recombinant Human IL-3 (100 ng/mL; PEPROTECH, Rocky Hill, NJ, USA) and a TLR7 agonist, imiquimod (R837) $(100 \mathrm{ng} / \mathrm{mL}$; InvivoGen, San Diego, CA, USA) or a TLR9 agonist, CpG ODN 2216 (5 $\mu \mathrm{g} / \mathrm{mL}$; Miltenyi Biotec, Bergisch Gladbach, Germany) for $6 \mathrm{~h}$ at $37^{\circ} \mathrm{C}$ in a $5 \% \mathrm{CO}_{2}$ incubator. GolgiPlug (100 ng/mL; BD Biosciences) was added during the final $3 \mathrm{~h}$ of stimulation to block cytokine secretion. After staining the cell-surface antigens, intracellular cytokines were stained using the BD Cytofix/Cytoperm Fixation/Permeabilization Solution Kit (BD Biosciences), anti-IFN- $\alpha$-APC (Miltenyi Biotec), and anti-tumor necrosis factor $\alpha$ (TNF- $\alpha$ )-PE-Cy7 (BD Biosciences), or their isotype control antibodies.

\section{Pretreatment with cytokines}

PBMCs were cultured in culture medium with IFN- $\alpha$ $(100 \mathrm{U} / \mathrm{mL})$ (R\&D Systems, Minneapolis, MN, USA) for $24 \mathrm{~h}$ at $37{ }^{\circ} \mathrm{C}$ in $5 \% \mathrm{CO}_{2}$. After pretreatment with IFN- $\alpha$, cells were stimulated with TLR agonists, and intracellular cytokine staining was performed as described above.

\section{Measurement of serum IFN- $a$}

Levels of serum IFN- $\alpha$ were determined in patients with SLE and in HC using VeriKine-HS Human Interferon
Alpha All Subtype ELISA Kit (PBL Assay Science, Piscataway Township, NJ, USA) according to the manufacturer's instructions.

\section{Confocal microscopy}

DCs were purified from PBMCs from patients with SLE and from $\mathrm{HC}$ using a Pan-DC Enrichment Kit (Miltenyi Biotec, Bergisch Gladbach, Germany) according to the manufacturer's instructions. Purified DCs were spun onto a microscope slide using the Thermo Shandon Cytospin 4 (Thermo Fisher scientific, MA, USA). DCs were fixed with $4 \%$ paraformaldehyde and then permeabilized with Triton X-100 (0.2\% Triton X-100 in PBS). Nonspecific background staining was prevented by incubating with Image-iT FX Signal Enhancer (Thermo Fisher scientific, MA, USA). Cells were incubated for $1.5 \mathrm{~h}$ at room temperature with primary antibodies: anti-TLR7 (Novus Biologicals, CO, USA), anti-BDCA2 (Novus Biologicals), anti-KDEL, anti-Early Endosome Antigen1 (EEA1), anti Rab7 and anti-lysosomal associated membrane protein-1 (LAMP1) (all from Abcam, MA, USA), and then washed and incubated for $1.5 \mathrm{~h}$ at room temperature with secondary antibodies: Alexa488donkey anti-mouse IgG, Alexa594-donkey anti-goat IgG and Alexa647-donkey anti-rabbit IgG ( all from Jackson ImmunoResearch Laboratories, PA, USA). Cell nuclei were stained with 4;6-diamidino-2-phenylindole (DAPI) (Sigma Aldrich, MO, USA) and mounted with Fluoromount/Plus (Diagnostic BioSystems, CA, USA). All samples were visualized using the FM1000D confocal laser scanning microscope (Olympus, Tokyo, Japan), and images were captured and analyzed using the FV10-ASW viewer (Olympus). pDCs were identified as BDCA2positive cells. Pearson's correlation was calculated using ImageJ, for quantitative analysis of the co-localization of TLR7 and endosomal markers (KDEL, EEA1, Rab7 and LAMP1).

\section{Statistical analysis}

All data were analyzed using GraphPad Prism (GraphPad, Inc., La Jolla, CA, USA) and differences between groups were analyzed using the Mann-Whitney $U$ test or Kruskal-Wallis test followed by Dunn's multiple comparisons test. The significance level was set at $p<0.05$. Associations between two variables were analyzed using Spearman correlation.

\section{Results}

IFN-a production by pDCs upon TLR9 stimulation was reduced and inversely correlated with disease activity in SLE

We first investigated IFN- $\alpha$ production by pDCs stimulated with a TLR9 ligand, CpG ODN2216 (hereafter 
referred to as CpG) in patients with SLE and HC. As previously reported by other groups [42-44], the percentages of IFN- $\alpha$-producing cells among pDCs were reduced in patients with SLE. Although there was no statistical difference in the percentages of IFN $-\alpha^{+}$pDCs between patients with inactive and active SLE, there was greater reduction in the percentage of IFN- $\alpha^{+} \mathrm{pDCs}$ in patients with active disease compared to in HC (Fig. 1a). pDCs also produced TNF- $\alpha$ when stimulated with CpG. TNF- $\alpha$ production by pDCs was decreased in patients with active disease, but not inactive disease, compared to HC. The percentage of IFN- $\alpha^{+}$TNF- $\alpha^{+}$pDCs was also decreased in patients with active disease. The IFN- $\alpha$ producing capacity by pDCs appears to be related to disease activity. The frequency of IFN- $\alpha^{+}$pDCs was negatively correlated with the SLEDAI (Fig. 1b). We also assessed whether the reduced IFN- $\alpha$ producing capacity of $\mathrm{pDCs}$ was related to the involvement of clinical manifestations. The percentages of IFN- $\alpha^{+} \mathrm{pDC}$ were reduced in all groups of patients with or without active glomerulonephritis or other clinical phenotypes (Fig. 1c).

IFN- $\alpha$ production by pDCs stimulated with a TLR7 agonist was increased and positively correlated with disease activity in SLE

Next, we evaluated whether IFN- $\alpha$ production by lupus pDCs was reduced following activation by other TLR pathways. Surprisingly, as shown in Fig. 2a, IFN- $\alpha$ production by pDCs was enhanced in SLE when stimulated with a TLR7 ligand, imiquimod, and there was a greater increase in the percentage of IFN- $\alpha^{+}$pDCs in patients with SLE with active disease compared to those with inactive disease. The percentage of IFN $-\alpha^{+}$TNF- $\alpha^{+}$pDCs was higher in patients with active disease. In addition, the percentage of IFN- $\alpha^{+}$pDCs was positively correlated with the SLEDAI (Fig. 2b). Although imiquimod stimulation induced TNF- $\alpha$ production by pDCs, there was no difference between $\mathrm{HC}$ and patients with SLE (Fig. 2a). The percentages of IFN- $\alpha^{+}$pDCs were higher in both patient groups with or without glomerulonephritis than in HC (Fig. 2c).

\section{Increased IFN- $a$ production by pDCs was not associated} with treatments in SLE

Immunosuppressive agents, including corticosteroids, could have an effect on the cytokine producing-capacity of pDCs. To investigate whether the medication affected the IFN- $\alpha$ production of $\mathrm{pDCs}$ in SLE, we compared the percentage of IFN- $\alpha^{+}$pDCs stimulated with $\mathrm{CpG}$ or imiquimod. There was a slight increase in the percentage of IFN- $\alpha^{+}$pDCs when stimulated with imiquimod among patients that had not received treatment, but there was

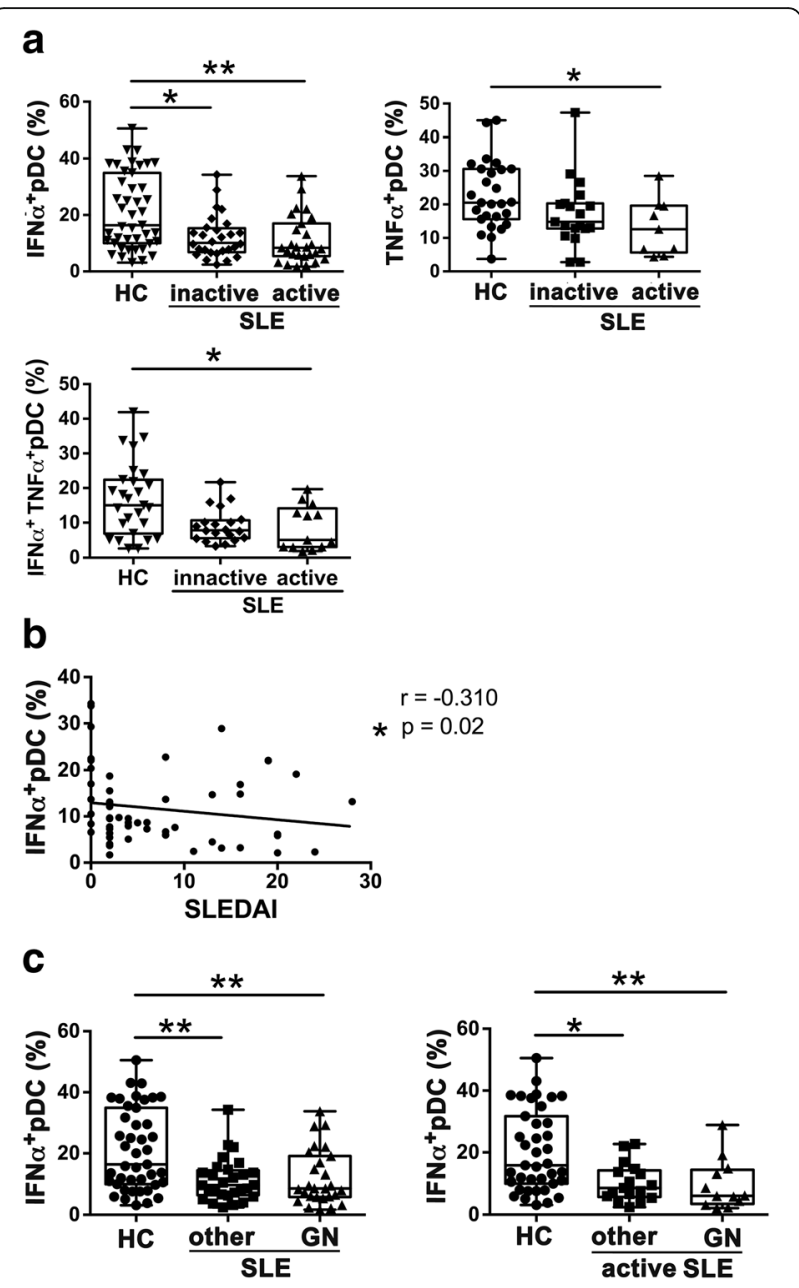

Fig. 1 Toll-like receptor (TLR)9-induced interferon-a (IFN-a) production by plasmacytoid dendritic cells (pDCs) was reduced and was inversely correlated with disease activity in systemic lupus erythematosus (SLE). Peripheral blood mononuclear cells (PBMCs) were stimulated with CpG ODN and cytokine producing pDCs were analyzed by flow cytometry in healthy controls $(\mathrm{HC})$ and patients with SLE with inactive or active disease. a The proportions of pDCs producing IFN-a, TNF-a, or both IFN- $a$ and TNF-a are shown. Each symbol represents the value of one individual. The box plot indicates the first and third quartiles and the middle line indicates the median. Whiskers indicate the minimum and maximum. ${ }^{*} p<0.05,{ }^{* *} p<0.01$ (Kruskal-Wallis test followed by Dunn's multiple comparisons test). $\mathbf{b}$ The correlation of the frequency of CpGinduced IFN-a-producing pDCs with SLE activity (SLE Disease Activity Index 2000 (SLEDAI)) score was examined using Spearman correlation. Each symbol represents the value of one individual. c Frequencies of CpG-induced IFN-a-producing pDCs were compared between patients with glomerulonephritis (GN) or other manifestations, in all patients (left) or in patients with active disease (right)

no statistically significant difference in the percentage of IFN $-\alpha^{+}$pDCs among patients under different treatment regimens (Fig. 3). The percentage of IFN- $\alpha^{+} \mathrm{pDCs}$ stimulated with $\mathrm{CpG}$ was also comparable among patient groups (Fig. 3). 


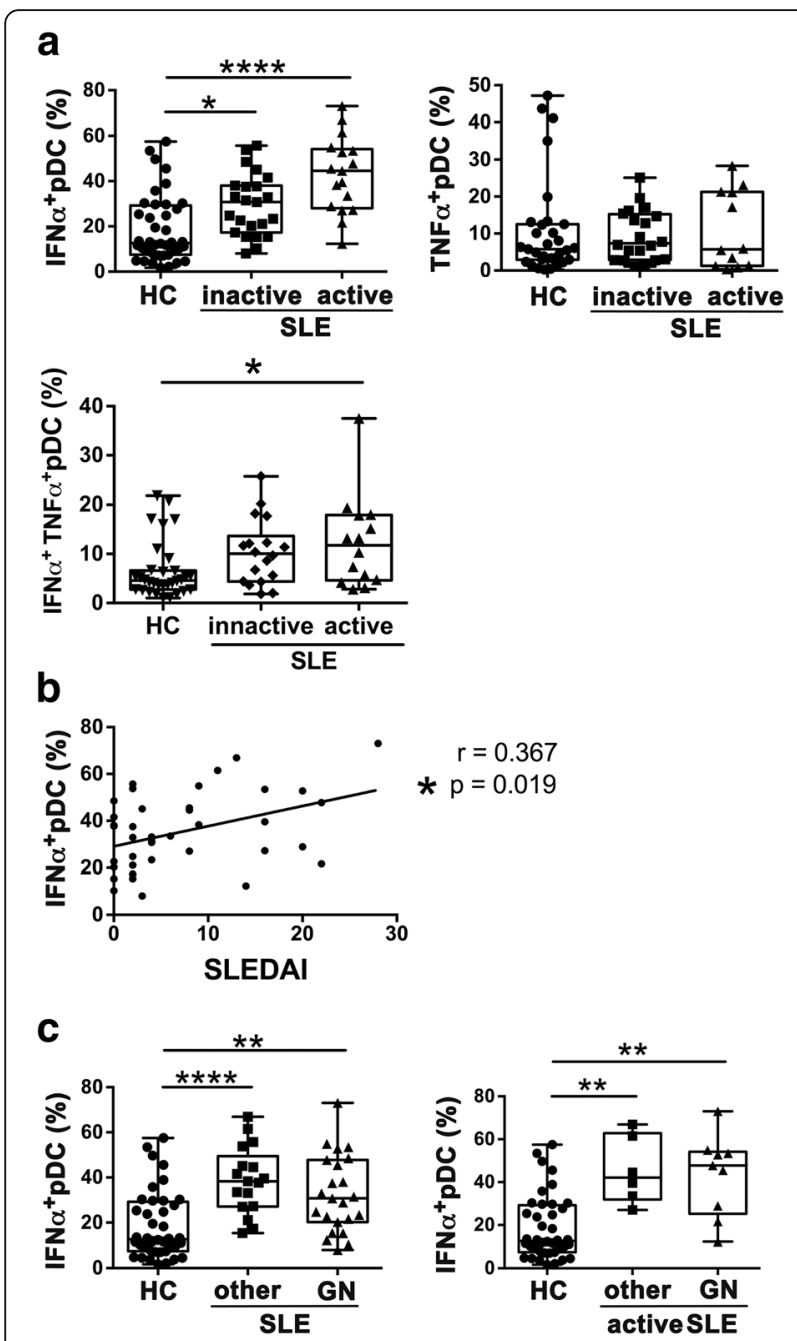

Fig. 2 Toll-like receptor 7 (TLR7)-induced interferon- a (IFN-a) production by plasmacytoid dendritic cells (pDCs) increased and was positively correlated with disease activity in systemic lupus erythematosus (SLE). Peripheral blood mononuclear cells (PBMCs) were stimulated with imiquimod and cytokine-producing pDCs were analyzed by flow cytometry in healthy controls $(\mathrm{HC})$ and patients with SLE with inactive or active disease. a The proportions of pDCs producing IFN-a, TNF-a, or both IFN- $a$ and TNF-a are shown. Each symbol represents the value of one individual. The box plot indicates the first and third quartiles and the middle line indicates the median. Whiskers indicate the minimum and maximum. ${ }^{*} p<0.05,{ }^{* *} p<0.01$, ${ }^{* * *} p<0.001$ (Kruskal-Wallis test followed by Dunn's multiple comparisons test). $\mathbf{b}$ The correlation of the frequency of imiquimod-induced INF-a-producing pDCs with SLE activity (SLE Disease Activity Index 2000 (SLEDAI)) score was examined using Spearman correlation. Each symbol represents the value of one individual. c Frequencies of imiquimod-induced IFN-a-producing pDCs were compared between patients with glomerulonephritis (GN) or other manifestations, in all patients (left) or in patients with active disease (right))

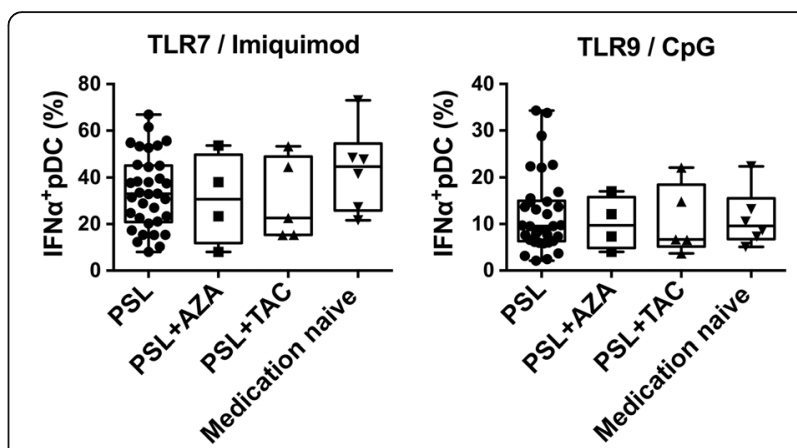

Fig. 3 Increased interferon-a (IFN-a) production by plasmacytoid dendritic cells (pDCs) was not associated with treatments in systemic lupus erythematosus (SLE). The proportions of pDCs producing IFN-a in patient groups receiving different medications from the data shown in Figs. 1 and 2; patient samples examined in both experiments are included. Each symbol represents the value of one individual. The box plot indicates the first and third quartiles and the middle line indicates the median. Whiskers indicate the minimum and maximum. ${ }^{*} p<0.05$, ${ }^{* *} p<0.01,{ }^{* * * *} p<0.001$ (Kruskal-Wallis test followed by Dunn's multiple comparisons test). PSL prednisone, AZA azathioprine, TAC tacrolimus

Serum IFN-a level positively correlates with IFN- $a$ producing capacity of imiquimod-stimulated pDCs in SLE IFN- $\alpha$ is known to be increased in the serum of patients with SLE. As previously reported, serum levels of IFN- $\alpha$ were increased in patients with SLE and were positively correlated with the SLEDAI (Fig. 4a). Thus, we next investigated whether IFN- $\alpha$ production by $\mathrm{pDCs}$ is related to the serum levels of IFN- $\alpha$. There was positive correlation between the serum level of IFN- $\alpha$ and frequency of IFN- $\alpha^{+}$pDCs stimulated with imiquimod (Fig. 4b). We also found that serum IFN- $\alpha$ levels were negatively correlated with the percentage of IFN $-\alpha^{+}$pDCs stimulated with CpG (Fig. 4b). These results suggest that elevated serum IFN- $\alpha$ is associated with the IFN- $\alpha$ producing capacity of lupus pDCs.

IFN- $\alpha$ enhanced IFN- $\alpha$ production of imiquimodstimulated $\mathrm{pDCs}$ and suppressed IFN-a production of CpG-stimulated pDCs

To examine whether elevated levels of IFN- $\alpha$ influence IFN- $\alpha$ production by pDCs in SLE, PBMCs from healthy volunteers were treated with IFN- $\alpha$ for $24 \mathrm{~h}$ and then IFN- $\alpha$ production by pDCs was measured after stimulation with $\mathrm{CpG}$ or imiquimod. Culture in medium without cytokines for $24 \mathrm{~h}$ reduced IFN- $\alpha$ production by pDCs upon stimulation with either imiquimod or CpG. Pretreatment with IFN- $\alpha$ enhanced IFN- $\alpha$ production by pDCs stimulated with imiquimod, but reduced CpGstimulated IFN- $\alpha$ production of pDCs (Fig. 5).

IFN-a production was observed only in stimulated pDCs We next evaluated spontaneous IFN- $\alpha$ production in pDCs and other immune cell subsets, including B cells, 


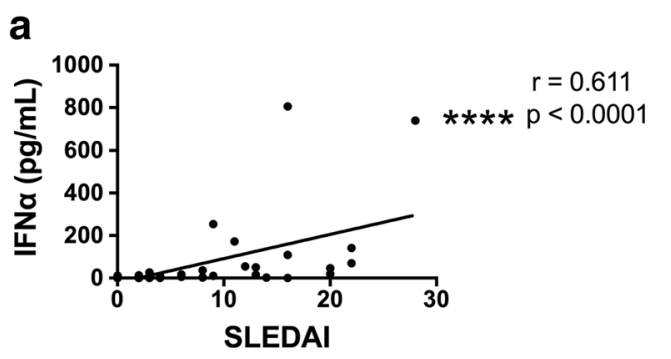

b

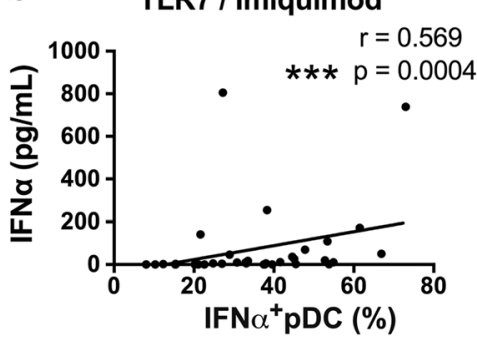

TLR9 / CpG

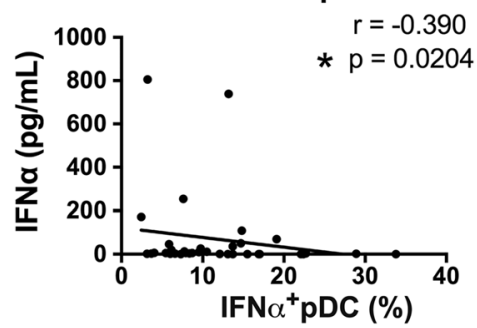

Fig. 4 Serum interferon- a (IFN-a) level is positively correlated with IFN-a producing capacity of imiquimod-stimulated plasmacytoid dendritic cells (pDCs) in systemic lupus erythematosus (SLE). Serum levels of IFN-a were measured by ELISA. The correlation of the serum IFN-a level with the SLE Disease Activity Index 2000 (SLEDAI) (a) and frequencies of CpG or imiquimod-induced IFN-a-producing pDCs (b) were examined by Spearman correlation

monocytes and conventional DCs (cDCs) and whether this might affect the cytokine-producing capacity of pDCs. Without stimulation, no cells produced IFN- $\alpha$ or TNF- $\alpha$ (Fig. 6). We also investigated IFN- $\alpha$ or TNF- $\alpha$ production by these cell subsets upon stimulation with CpG or imiquimod. Monocytes and cDCs produced TNF- $\alpha$ upon stimulation, but none of the cells except pDCs produced IFN- $\alpha$ (Fig. 6).

TLR7 localization was increased in late endsomal and lysosomeal compartments in pDCs from patients with SLE It is known that the TLR7 and TLR9 signaling pathways are regulated by their localization in the ensosomal compartments and IFN- $\alpha$ production requires TLR trafficking to lysosome-related organelle [47]. To understand why IFN- $\alpha$ production of $\mathrm{pDC}$ stimulated with a TLR7 agonist was increased in SLE, we investigated the localization of TLR7 in pDC from HC and patients with SLE. Co-localization of TLR7 with KDEL (endoplasmic reticulum marker) or EEA1 (early endosome marker) was comparable between $\mathrm{pDCs}$ from $\mathrm{HC}$ and patients with SLE (Fig. 7). On the other hand, co-localization between TLR7 and Rab7 (late endosome marker) or LAMP1 (lysosome marker) was increased in pDCs from patients with SLE compared to those from HC (Fig. 7). In pDCs from two patients with SLE with active disease,

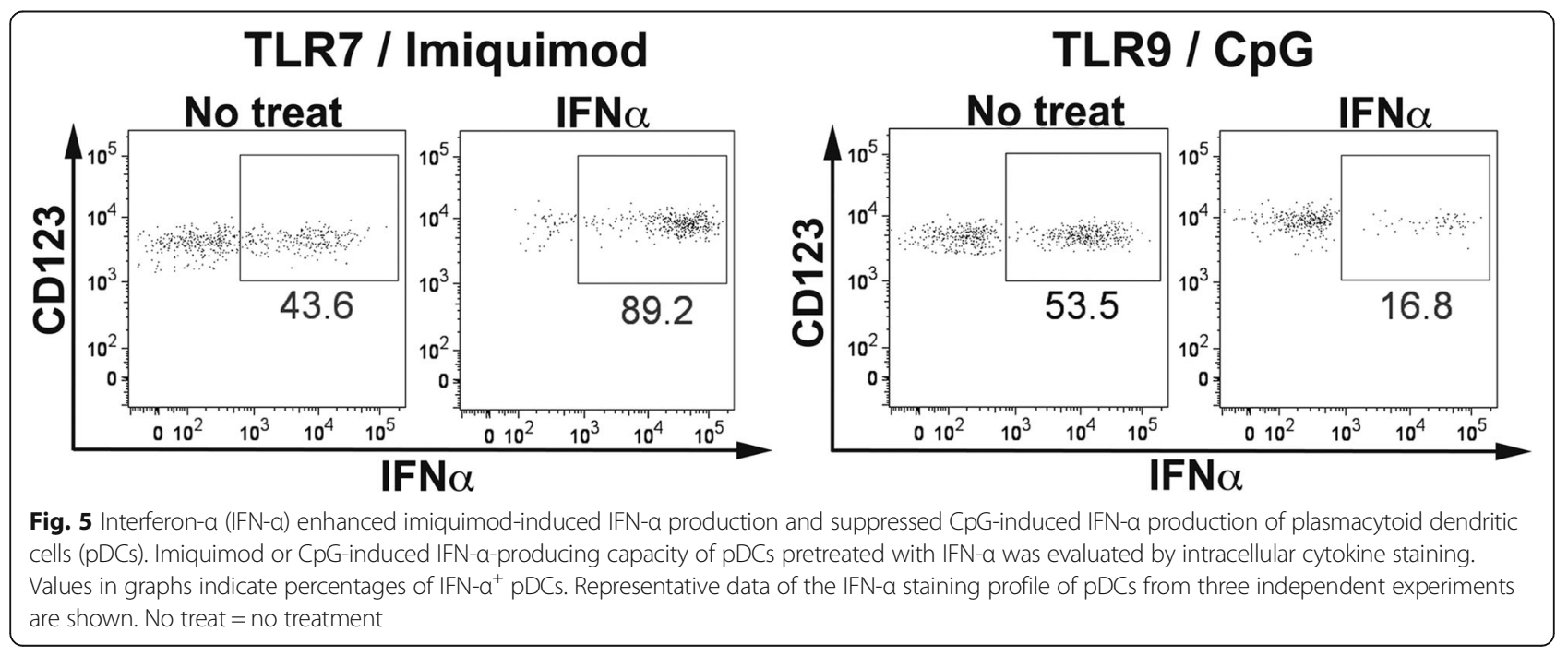




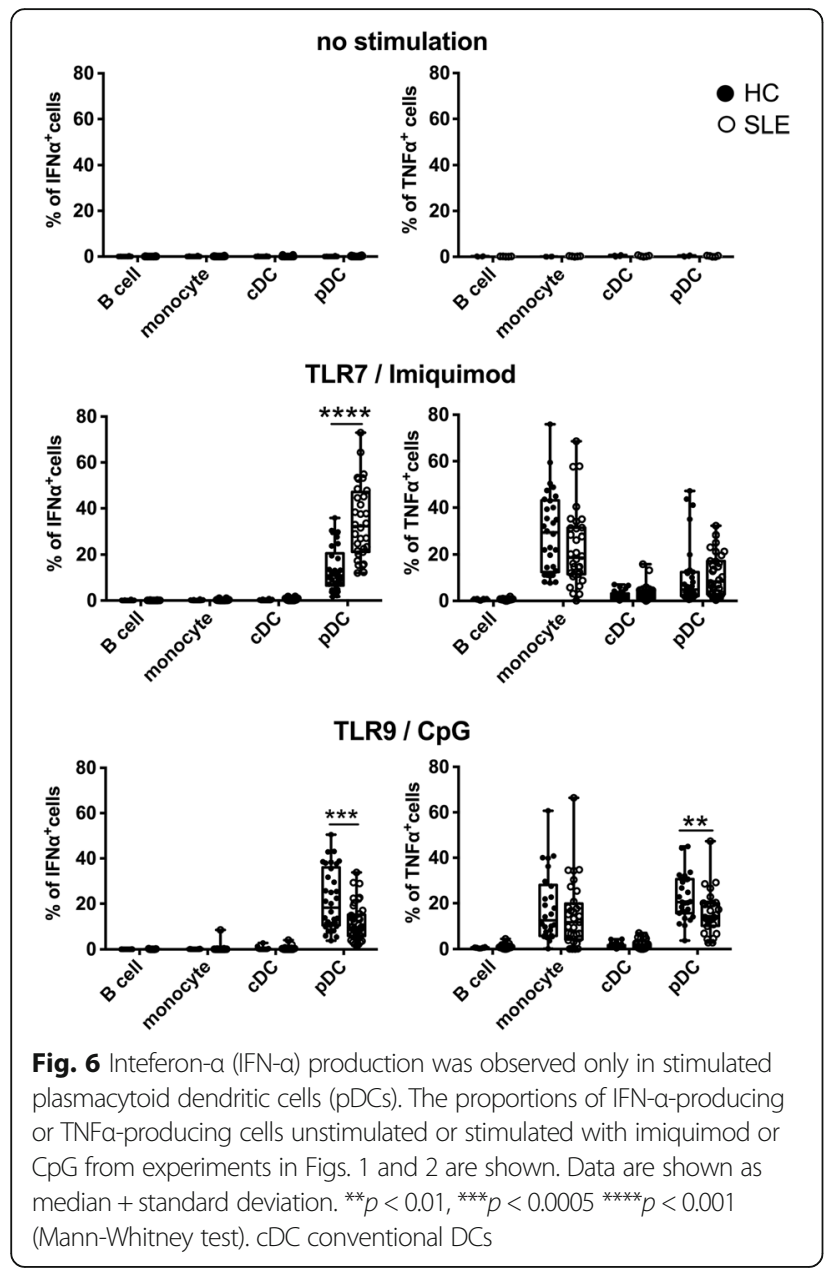

co-localization of TLR7 seemed to be more increased with LAMP1 than KDEL. The Pearson's correlation coefficient of TLR7 and LAMP1 was 0.706 and 0.668 , whereas that of TLR7 and KDEL was 0.314 and 0.462 . These results indicate that increased localization of TLR7 in lysosome may also be related to augmented IFN- $\alpha$ production of lupus pDCs stimulated with a TLR7 agonist.

\section{Discussion}

Despite the increased levels of IFN- $\alpha$ in patients with SLE, previous studies showed either decreased or comparable IFN- $\alpha$-producing capacity of lupus pDCs compared to healthy controls [40-45]. As previously reported, lupus pDCs produced lower levels of IFN- $\alpha$ after stimulation with a TLR9 agonist. However, the proportion of IFN- $\alpha-$ producing pDCs was greatly increased in patients with SLE when pDCs were activated with a TLR7 agonist. We also showed that the IFN- $\alpha$-producing capacity of pDCs was associated with disease activity and serum IFN- $\alpha$ levels. We showed that exposure to IFN- $\alpha$ enhanced IFN$\alpha$ production upon TLR7 stimulation, but reduced TLR9induced IFN $-\alpha$ production. We further demonstrated that more TLR7 localized in late endosome and lysosome in pDCs from patients with SLE. These findings suggest that the enhanced IFN- $\alpha$-producing capacity of pDCs resulting from increased TLR7 signaling was further augmented by exposure to IFN- $\alpha$ in SLE. Because animal studies showed that TLR7 plays an important role in disease progression [48-51], enhanced IFN- $\alpha$ production by pDCs may be associated with the pathogenesis of SLE. In this study, we tested the responses of pDCs against an artificial TLR7 ligand, imiquimod. It would be more informative to examine the responses of lupus pDCs against more pathophysiological ligands such as single-stranded RNA or RNA-IgG immune complexes.

The SLEDAI was positively correlated with both serum levels of IFN- $\alpha$ and frequencies of IFN- $\alpha^{+}$pDCs stimulated with a TLR7 agonist. As IFN- $\alpha$ activates pDCs through the interferon receptor $[52,53]$, we evaluated whether IFN- $\alpha$ exposure enhances IFN- $\alpha$ production of pDCs. As expected, after in vitro treatment with IFN- $\alpha$, the frequency of IFN- $\alpha^{+}$pDCs stimulated with a TLR7 agonist was increased and TLR9-induced IFN- $\alpha$ production by $\mathrm{pDCs}$ was reduced. Because serum IFN- $\alpha$ is associated with the SLEDAI, the increased IFN- $\alpha^{+}$ production by pDCs after stimulation with a TLR7 agonist in patients with active disease may be due to prior exposure to IFN- $\alpha$ in vivo. Among other immune cell types tested, IFN- $\alpha$ production was only observed in pDCs. Thus, IFN- $\alpha$ production by stimulated pDCs could be modified by the IFN- $\alpha$ produced by themselves. Other cells, including monocytes and cDCs responded to TLR7 or TLR9 stimulation. Therefore, IFN- $\alpha$ production by pDCs could be affected by other cells activated by a TLR agonist through different mechanisms.

The decreased production of IFN- $\alpha$ by lupus pDCs upon TLR9 activation has been reported by other groups [43-45]. Prior exposure of pDCs to either a TLR9 agonist or lupus serum reduces IFN- $\alpha$ production by these cells. Because the levels of immune complexes in lupus sera are inversely correlated with $\mathrm{CpG}$-induced IFN- $\alpha$ production in lupus PBMCs, pDCs activated in vivo, most likely through TLR9 stimulation with IC containing DNA, may become tolerant to further stimulation [44]. In our study, reduced CpG-induced IFN- $\alpha$ production by $\mathrm{pDCs}$ was negatively correlated with the SLEDAI. Therefore, such pDCs stimulated with IC in vivo may show a low response to further in vitro stimulation. However, pretreatment of pDCs with IFN- $\alpha$ reduced $C$ pG-induced IFN- $\alpha$ production of these cells. In addition, the frequency of CpGinduced IFN- $\alpha^{+}$pDCs was negatively correlated with the levels of serum IFN- $\alpha$. This supports that the reduction of CpG-induced IFN- $\alpha^{+}$pDCs is associated with increased IFN- $\alpha$ levels in SLE.

IFN- $\beta$ has been demonstrated to upregulate TLR7 in pDCs, but not in other cell subsets including monocytes, 
a

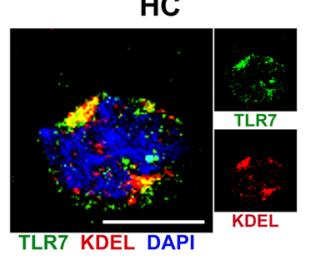

C

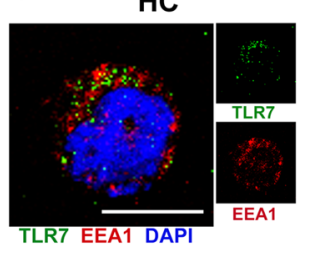

e

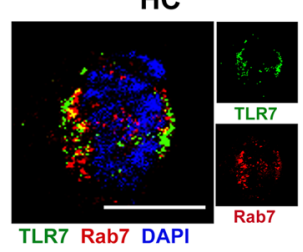

$\mathbf{g}$

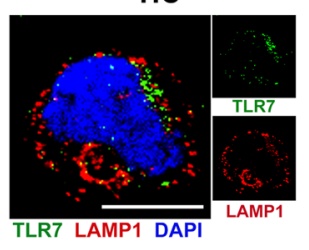

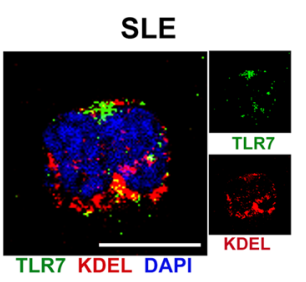
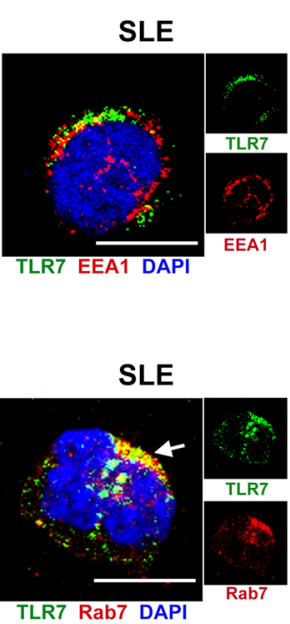

SLE

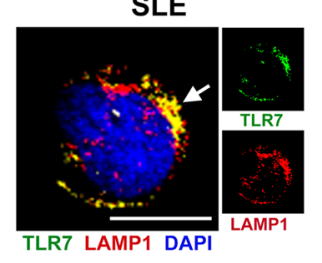

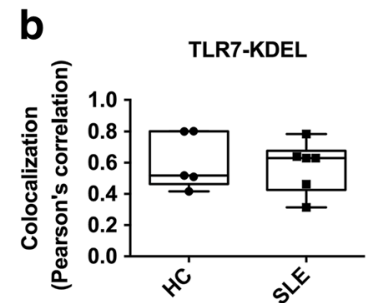

d
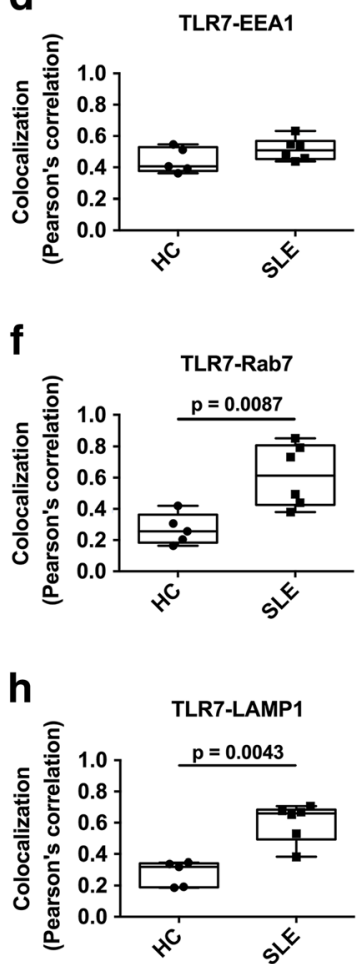

Fig. 7 Enhanced localization of Toll-like receptor 7 (TLR7) in late endosomal and lysosomal compartments in lupus plasmacytoid dendritic cells (pDCs). (a-h) DCs from healthy controls (HC) or patients with systemic lupus erythematosus (SLE) stained with antibodies to BDCA2, TLR7, KDEL and EEA1, Rab7, LAMP1 and DAPI (blue). Representative images of BDCA2-positive pDCs from HC and pPatients with SLE stained with TLR7 (green) and indicated markers (red) of endocytic pathways are shown $(\mathbf{a}, \mathbf{c}, \mathbf{e}, \mathbf{g})$. Scale bars indicate $5.0 \mu \mathrm{m}$ and white arrows indicate robust co-localization of TLR7 with Rab7 and LAMP1. Quantificaion of co-localization between TLR7 and KDEL (b), EEA1 (d), Rab7 (f) and LAMP1 (h) is shown. Each symbol represents the value of one individual. The box plot indicates the first and third quartiles and the middle line indicates the median. Whiskers indicate the minimum and maximum. The Mann-Whitney test was used to test for the differences between pDCs from $\mathrm{HC}$ and patients with SLE

myeloid DCs, B cells, and T cells [54]. In vivo treatment with IFN- $\beta$ induces TLR7 upregulation and TLR9 down modulation in PBMCs of patients with multiple sclerosis [54]. IFN- $\alpha$ may have similar effects on TLR expression by pDCs in SLE. Further studies on the effect of IFN- $\alpha$ on the expression of TLRs may be important to understand the IFN- $\alpha$-producing capacity of lupus pDCs.

TLR7 and TLR9 share downstream signaling pathways [55]. The first pathway requiring nuclear factor $\mathrm{kB}$ activation leads to production of proinflammatory cytokines such as IL-12 and TNF- $\alpha$. The second pathway leads to the IRF7-dependent production of type I IFN. TNF- $\alpha$ production by pDCs was comparable between $\mathrm{HC}$ and patients with SLE both after TLR7 and TLR9 stimulation. However, although lupus pDCs responded strongly to imiquimod stimulation and produced higher levels of IFN- $\alpha$, they produced decreased levels of IFN- $\alpha$ when stimulated with CpG. This second pathway requires trafficking of TLRs from early endosome to lysosome-related organelle. As we found increased TLR7 co-localization with Rab7 and LAMP1 in pDCs from patients with SLE, the IRF signaling pathway appeared to be more active in lupus pDCs. As good antibodies against TLR9 were not commercially available, we were not able to investigate the location of TLR9 in cellular compartments. Thus, why lupus pDCs responded in an opposite manner in terms of 
IFN- $\alpha$ production after stimulation of similar signaling pathways requires further analysis. Uncoordinated 93 homolog B1 (UNC93B1) is an important molecule for endosomal TLR trafficking, and UNC93B1 discriminates between TLR7 and TLR9 [56]. Therefore, TLR chaperones and trafficking factors may be related to the IFN- $\alpha$-producing capacity of lupus pDCs. It is also not known how exposure to IFN- $\alpha$ regulates the TLR7/9 downstream pathway or which other mechanisms are involved in IFN- $\alpha$ production by $\mathrm{pDCs}$ in SLE. TLR9 has been suggested to be the main receptor for IC-containing DNA in SLE. More recent studies indicated that DNA binds to other nucleic acid receptors present in the cytoplasm [57]. Therefore, the responses of pDCs to other nucleic acid receptors in SLE remain unclear.

In murine lupus models, the role of TLR9 in the pathogenesis is unclear. TLR9 has been suggested to be required for the generation of autoantibodies against DNA [58], but TLR9 deficiency results in increased IFN- $\alpha$ and antibody levels, and disease exacerbation [48, 59, 60]. In contrast, several reports indicate that TLR7 is involved in the progression of autoimmune responses [48-51]. Deletion of TLR7 in MRL/lpr mice has been shown to reduce antibody production and nephritis [48]. Mice bearing the Y chromosome-linked genomic modifier Yaa, overexpress TLR7, which promotes autoreactive and inflammatory responses $[50,51]$. Together with the results of human genetic studies identifying TLR7 and its signaling molecules as susceptible genes, the TLR7 pathway appears to play an important role in the pathogenesis of SLE.

\section{Conclusions}

In the present study, we demonstrated that the enhanced IFN- $\alpha$ production by pDCs stimulated with a TLR7 agonist was associated with increased TLR7 location in late endosome and lysosome compartments in pDCs from patients with SLE. The importance of the TLR7 pathway and the role of pDCs in lupus pathology have been suggested in animal studies and human genetic studies $[61,62]$. We observed enhanced TLR7 responses, further indicating involvement of the TLR7 pathway in the pathogenesis of SLE.

\section{Additional files}

Additional file 1: Table S1. Characteristics of $\mathrm{HC}$ and lupus patients for confocal microscopic analysis. Values are $\mathrm{n}$ or median [interquartile range]. (DOCX $30 \mathrm{~kb}$ )

Additional file 2: Figure S1. Gating strategy of pDCs is shown. pDCs were identified as Zombie dye $\mathrm{CD}^{-} \mathrm{CD}^{-19} \mathrm{CD}^{-} 4^{-} \mathrm{CD}^{\circ} 6^{-} \mathrm{HLADR}^{+} \mathrm{CD} 11 \mathrm{C}^{-}$ $\mathrm{CD} 123^{+}$. (TIF $\left.2794 \mathrm{~kb}\right)$

\section{Abbreviations}

CpG ODN: CpG oligodeoxyribonucleotide; ELISA: Enzyme-linked immunosorbent assay; HC: Healthy controls; IFN: Interferon; IL: Interleukin; PBMC: Peripheral blood mononuclear cell; PBS: Phosphate-buffered saline; pDC: Plasmacytoid dendritic cells; SLE: Systemic lupus erythematosus; SLEDAI: Systemic Lupus Erythematosus disease activity index; TLR: Toll-like receptor; TNF: Tumor necrosis factor

\section{Acknowledgments}

We would like thank Prof. Kensuke Miyake (Tokyo University, Tokyo, Japan) for providing transfectants expressing human TLR7 or TLR9 that were used to test specificity of anti-TLR7 antibody. We also thank Ran Matudaira, Manami Seki and all members of the Department of Rheumatology, Juntendo University School of Medicine for the recruitment of study patients.

\section{Funding}

This study was supported by the Japan Society for the Promotion of Science (Grant-in-Aid for Scientific Research (C) 26461473 to Asako Chiba, Grant-in-Aid for Scientific Research (B) 2629324 to Sachiko Miyake.

\section{Availability of data and materials}

The datasets used and/or analyzed during the current study are available from the corresponding author on reasonable request.

\section{Authors' contributions}

$A C$ and SM designed the research and wrote the manuscript. GM and NF performed the experiments and analyzed the data. GM, KY, and NT selected patients and conducted clinical diagnosis. All authors contributed to the interpretation of the data and preparation of the manuscript. All authors read and approved the final manuscript.

\section{Ethics approval and consent to participate}

This study was conducted with the approval of the regional ethics committee at Juntendo University Hospital (No.334). Informed consent was obtained from all patients and healthy volunteers.

Consent for publication

Not applicable.

\section{Competing interests}

The authors declare that they have no competing interests.

\section{Publisher's Note}

Springer Nature remains neutral with regard to jurisdictional claims in published maps and institutional affiliations.

\section{Author details}

'Department of Immunology, Juntendo University School of Medicine, 2-2-1 Hongo, Bunkyo-ku, Tokyo 113-8421, Japan. ${ }^{2}$ Department of Internal Medicine and Rheumatology, Juntendo University School of Medicine, Tokyo, Japan.

Received: 29 March 2017 Accepted: 21 September 2017 Published online: 19 October 2017

\section{References}

1. Crow MK. Type I Interferon in the pathogenesis of Lupus. J Immunol. 2014;192:5459-68.

2. Lauwerys BR, Ducreux J, Houssiau FA. Type I interferon blockade in systemic lupus erythematosus: where do we stand? Rheumatology. 2014;53:1369-76.

3. Rönnblom L, Alm GV, Eloranta ML. The type I interferon system in the development of lupus. Semin Immunol. 2011;23:113-21.

4. Mathian A, Weinberg A, Gallegos M, Banchereau J, Koutouzov S. IFN-a induces early lethal lupus in preautoimmune (New Zealand Black x New Zealand White) F1 but not in BALB/c mice. J Immunol. 2005;174:2499-506.

5. Santiago-Raber ML, Baccala R, Haraldsson KM, Choubey D, Stewart TA, Kono $\mathrm{DH}$, Theofilopoulos AN. Type-I interferon receptor deficiency reduces lupuslike disease in NZB mice. J Exp Med. 2003;197:777-88.

6. Braun D, Geraldes P, Demengeot J. Type I interferon controls the onset and severity of autoimmune manifestations in Ipr mice. J Autoimmun. 2003;20:15-25. 
7. Rönnblom LE, Alm GV, Oberg KE. Autoimmunity after alpha-interferon therapy for malignant carcinoid tumors. Ann Intern Med. 1991;115:178-83.

8. Ehrenstein MR, McSweeney E, Swane M, Worman CP, Goldstone AH, Isenberg DA. Appearance of anti-DNA antibodies in patients treated with interferon-a. Arthritis Rheum. 1993;36:279-80.

9. Kälkner KM, Rönnblom L, Karlsson Parra AK, Bengtsson M, Olsson Y, et al. Antibodies against double-stranded DNA and development of polymyositis during treatment with interferon. QJMed. 1998;91:393-9.

10. Hooks JJ, Moutsopoulos HM, Geis SA, Stahl NI, Decker JL, Notkins AL. Immune interferon in the circulation of patients with autoimmune disease. N Engl J Med. 1979;301:5-8.

11. Ytterberg SR, Schnitzer TJ. Serum interferon levels in patients with systemic lupus erythematosus. Arthritis Rheum. 1982;25:401-6.

12. Bengtsson AA, Sturfelt $G$, Truedsson L, Blomberg J, Alm G, Vallin H, et al. Activation of type I interferon system in systemic lupus erythematosus correlates with disease activity but not with antiretroviral antibodies. Lupus. 2000;9:664-71.

13. Niewold TB, Adler JE, Glenn SB, Lehman TJ, Harley JB, Crow MK. Age- and sex-related patterns of serum interferon-a activity in lupus families. Arthritis Rheum. 2008;58:2113-9.

14. Bennett L, Palucka AK, Arce E, Cantrell V, Borvak J, Banchereau J, et al. Interferon and granulopoiesis signatures in systemic lupus erythematosus blood. J Exp Med. 2003;197:711-23.

15. Baechler EC, Batliwalla FM, Karypis G, Gaffney PM, Ortmann WA, Espe KJ, et al. Interferon-inducible gene expression signature in peripheral blood cells of patients with severe lupus. Proc Natl Acad Sci U S A. 2003;100:2610-5.

16. Crow MK, Kirou KA, Wohlgemuth J. Microarray analysis of interferon-regulated genes in SLE. Autoimmunity. 2003;36:481-90.

17. Han GM, Chen SL, Shen N, Ye S, Bao CD, Gu YY. Analysis of gene expression profiles in human systemic lupus erythematosus using oligonucleotide microarray. Genes Immun. 2003;4:177-86.

18. Kirou KA, Lee C, George S, Louca K, Papagiannis IG, Peterson MG, Ly N, Woodward RN, Fry KE, Lau AY, Prentice JG, Wohlgemuth JG, Crow MK. Coordinate overexpression of interferon-a-induced genes in systemic lupus erythematosus. Arthritis Rheum. 2004;50:3958-67.

19. Kirou KA, Lee C, George S, Louca K, Peterson MG, Crow MK. Activation of the interferon-a pathway identifies a subgroup of systemic lupus erythematosus patients with distinct serologic features and active disease. Arthritis Rheum. 2005;52:1491-503.

20. Graham RR, Kozyrev SV, Baechler EC, Reddy MV, Plenge RM, Bauer JW, et al. A common haplotype of interferon regulatory factor 5 (IRF5) regulates splicing and expression and is associated with increased risk of systemic lupus erythematosus. Nat Genet. 2006;38:550-5.

21. Harley JB, Alarcon-Riquelme ME, Criswell LA, Jacob CO, Kimberly RP, Moser $\mathrm{KL}$, et al. Genome-wide association scan in women with systemic lupus erythematosus identifies susceptibility variants in ITGAM, PXK, KIAA1542 and other loci. Nat Genet. 2008:40:204-10.

22. Hom G, Graham RR, Modrek B, Taylor KE, Ortmann W, Garnier S, et al. Association of systemic lupus erythematosus with C8orf13-BLK and ITGAMITGAX. N Engl J Med. 2008;358:900-9.

23. Shen N, Fu Q, Deng Y, Qian X, Zhao J, Kaufman KM, et al. Sex-specific association of $X$-linked Toll-like receptor 7 (TLR7) with male systemic lupus erythematosus. Proc Natl Acad Sci U S A. 2010;107:15838-43.

24. Kawasaki A, Furukawa $H$, Kondo $Y$, Ito S, Hayashi T, Kusaoi M, et al. TLR7 single-nucleotide polymorphisms in the $3^{\prime}$ untranslated region and intron 2 independently contribute to systemic lupus erythematosus in Japanese women: a case-control association study. Arthritis Res Ther. 2011;13:R41.

25. Sigurdsson S, Nordmark G, Goring HH, Lindroos K, Wiman AC, Sturfelt G, et al. Polymorphisms in the tyrosine kinase 2 and interferon regulatory factor 5 genes are associated with systemic lupus erythematosus. Am J Hum Genet. 2005;76:528-37.

26. Graham RR, Kyogoku C, Sigurdsson S, Vlasova IA, Davies LR, Baechler EC, et al. Three functional variants of IFN regulatory factor 5 (IRF5) define risk and protective haplotypes for human lupus. Proc Natl Acad Sci U S A. 2007;104:6758-63.

27. Niewold TB, Kelly JA, Flesch MH, Espinoza LR, Harley JB, Crow MK. Association of the IRF5 risk haplotype with high serum interferon-a activity in systemic lupus erythematosus patients. Arthritis Rheum. 2008:58:2481-7.

28. Cherian TS, Kariuki SN, Franek BS, Buyon JP, Clancy RM, Niewold TB. Brief Report: IRF5 systemic lupus erythematosus risk haplotype is associated with asymptomatic serologic autoimmunity and progression to clinical autoimmunity in mothers of children with neonatal lupus. Arthritis Rheum. 2012;64:3383-7.

29. Hughes T, Adler A, Kelly JA, Kaufman KM, Williams AH, Langefeld CD, et al. Evidence for gene-gene epistatic interactions among susceptibility loci for systemic lupus erythematosus. Arthritis Rheum. 2012;64:485-92.

30. Salloum R, Franek BS, Kariuki SN, Rhee L, Mikolaitis RA, Jolly M, et al. Genetic variation at the IRF7/PHRF1 locus is associated with autoantibody profile and serum interferon-a activity in lupus patients. Arthritis Rheum. 2010;62:553-61.

31. Rullo OJ, Woo JM, Wu H, Hoftman AD, Maranian P, Brahn BA, et al. Association of IRF5 polymorphisms with activation of the interferon a pathway. Ann Rheum Dis. 2010;69:611-7.

32. Cella M, Jarrossay D, Facchetti F, Alebardi O, Nakajima H, Lanzavecchia A, et al. Plasmacytoid monocytes migrate to inflamed lymph nodes and produce large amounts of type I interferon. Nat Med. 1999:5:919-23.

33. Siegal FP, Kadowaki N, Shodell M, Fitzgerald-Bocarsly PA, Shah K, Ho S, et al. The nature of the principal type 1 interferon-producing cells in human blood. Science. 1999;284:1835-7

34. Colonna M, Trinchieri G, Liu YJ. Plasmacytoid dendritic cells in immunity. Nat Immunol. 2004;5:1219-26.

35. Kawai T, Akira S. The role of pattern-recognition receptors in innate immunity: update on Toll-like receptors. Nat Immunol. 2010;11:373-84.

36. Lövgren T, Eloranta ML, Båve U, Alm GV, Rönnblom L. Induction of interferon-a production in plasmacytoid dendritic cells by immune complexes containing nucleic acid released by necrotic or late apoptotic cells and lupus lgG. Arthritis Rheum. 2004;50:1861-72

37. Barrat FJ, Meeker T, Gregorio J, Chan JH, Uematsu S, Akira S, Chang B, Duramad O, Coffman RL. Nucleic acids of mammalian origin can act as endogenous ligands for Toll-like receptors and may promote systemic lupus erythematosus. J Exp Med. 2005;202:1131-9.

38. Means TK, Latz E, Hayashi F, Murali MR, Golenbock DT, Luster AD. Human lupus autoantibody-DNA complexes activate DCs through cooperation of CD32 and TLR9. J Clin Invest. 2005;115:407-17.

39. Lövgren T, Eloranta ML, Kastner B, Wahren-Herlenius M, Alm GV, Rönnblom L. Induction of interferon-a by immune complexes or liposomes containing systemic lupus erythematosus autoantigen- and Sjögren's syndrome autoantigen-associated RNA. Arthritis Rheum. 2006;54:1917-27.

40. Blanco P, Palucka AK, Gill M, Pascual V, Banchereau J. Induction of dendritic cell differentiation by IFN-a in systemic lupus erythematosus. Science. 2001;294:1540-3.

41. Cederblad B, Blomberg S, Vallin H, Perers A, Alm GV, Rönnblom L. Patients with systemic lupus erythematosus have reduced numbers of circulating natural interferon-a-producing cells. J Autoimmun. 1998;11:465-70.

42. Blomberg S, Eloranta ML, Magnusson M, Alm GV, Rönnblom L. Expression of the markers BDCA-2 and BDCA-4 and production of interferon- $a$ by plasmacytoid dendritic cells in systemic lupus erythematosus. Arthritis Rheum. 2003:48:2524-32.

43. Zeuner RA, Klinman DM, Illei G, Yarboro C, Ishii KJ, Gursel M, Verthelyi D. Response of peripheral blood mononuclear cells from lupus patients to stimulation by CPG oligodeoxynucleotides. Rheumatology. 2003;42:563-9.

44. Kwok SK, Lee JY, Park SH, Cho ML, Min SY, Park SH, et al. Dysfunctional interferon-a production by peripheral plasmacytoid dendritic cells upon Toll-like receptor-9 stimulation in patients with systemic lupus erythematosus. Arthritis Res Ther. 2008:10:R29.

45. Sacre K, Criswell LA, McCune JM. Hydroxychloroquine is associated with impaired interferon-alpha and tumor necrosis factor-alpha production by plasmacytoid dendritic cells in systemic lupus erythematosus. Arthritis Res Ther. 2012;14:R155.

46. Gladman DD, Ibañez D, Urowitz MB. Systemic lupus erythematosus disease activity index 2000. J Rheumatol. 2002;29:288-91.

47. Sasai M, Linehan MM, Iwasaki A. Bifurcation of Toll-like receptor 9 signaling by adaptor protein 3. Science. 2010;329:1530-4.

48. Christensen SR, Shupe J, Nickerson K, Kashgarian M, Flavell RA, Shlomchik MJ. Toll-like receptor 7 and TLR9 dictate autoantibody specificity and have opposing inflammatory and regulatory roles in a murine model of lupus. Immunity. 2006;25:417-28.

49. Nickerson KM, Christensen SR, Shupe J, Kashgarian M, Kim D, Elkon K, Shlomchik MJ. TLR9 regulates TLR7- and MyD88-dependent autoantibody production and disease in a murine model of lupus. J Immunol. 2010;184:1840-8. 
50. Deane JA, Pisitkun P, Barrett RS, Feigenbaum L, Town T, Ward JM, Flavell RA, Bolland S. Control of toll-like receptor 7 expression is essential to restrict autoimmunity and dendritic cell proliferation. Immunity. 2007;27:801-10.

51. Pisitkun P, Deane JA, Difilippantonio MJ, Tarasenko T, Satterthwaite AB, Bolland S. Autoreactive B cell responses to RNA-related antigens due to TLR7 gene duplication. Science. 2006;312:1669-72.

52. Sato M, Hata N, Asagiri M, Nakaya T, Taniguchi T, Tanaka N. Positive feedback regulation of type I IFN genes by the IFN-inducible transcription factor IRF-7. FEBS Lett. 1998;441:106-10.

53. Marié I, Durbin JE, Levy DE. Differential viral induction of distinct interferona genes by positive feedback through interferon regulatory factor-7. EMBO J. 1998;17:6660-9.

54. Derkow K, Bauer JM, Hecker M, Paap BK, Thamilarasan M, Koczan D, Schott E, Deuschle K, Bellmann-Strobl J, Paul F, Zettl UK, Ruprecht K, Lehnardt S. Multiple sclerosis: modulation of toll-like receptor (TLR) expression by interferon- $\beta$ includes upregulation of TLR7 in plasmacytoid dendritic cells. PLoS One. 2013;8:e70626.

55. Blasius AL, Beutler B. Intracellular Toll-like receptors. Immunity. 2010;32:305-15.

56. Fukui R, Saitoh S, Kanno A, Onji M, Shibata T, Ito A, Onji M, Matsumoto M, Akira S, Yoshida N, Miyake K. Unc93B1 restricts systemic lethal inflammation by orchestrating Toll-like receptor 7 and 9 trafficking. Immunity. 2011;35:69-81.

57. Crowl JT, Gray EE, Pestal K, Volkman HE, Stetson DB. Intracellular nucleic acid detection in autoimmunity. Annu Rev Immunol. 2017;35:313-36.

58. Christensen SR, Kashgarian M, Alexopoulou L, Flavell RA, Akira S, Shlomchik MJ. Toll-like receptor 9 controls anti-DNA autoantibody production in murine lupus. J Exp Med. 2005;202:321-31.

59. Wu X, Peng SL. Toll-like receptor 9 signaling protects against murine lupus. Arthritis Rheum. 2006;54:336-42.

60. Lartigue A, Courville P, Auquit I, François A, Arnoult C, Tron F, Gilbert D, Musette P. Role of TLR9 in anti-nucleosome and anti-DNA antibody production in /pr mutation-induced murine lupus. J Immunol. 2006;177:1349-54.

61. Rowland SL, Riggs JM, Gilfillan S, Bugatti M, Vermi W, Kolbeck R, Unanue ER, Sanjuan MA, Colonna M. Early, transient depletion of plasmacytoid dendritic cells ameliorates autoimmunity in a lupus model. J Exp Med. 2014;211:1977-91.

62. Sisirak V, Ganguly D, Lewis KL, Couillault C, Tanaka L, Bolland S, D'Agati V, Elkon KB, Reizis B. Genetic evidence for the role of plasmacytoid dendritic cells in systemic lupus erythematosus. J Exp Med. 2014;211:1969-76.

\section{Submit your next manuscript to BioMed Central and we will help you at every step:}

- We accept pre-submission inquiries

- Our selector tool helps you to find the most relevant journal

- We provide round the clock customer support

- Convenient online submission

- Thorough peer review

- Inclusion in PubMed and all major indexing services

- Maximum visibility for your research

Submit your manuscript at www.biomedcentral.com/submit 